\title{
Thermochromic Coatings for Intelligent Architectural Glazing
}

Ivan P. Parkin 1, a , Russell Binions ${ }^{1}$, Clara Piccirillo ${ }^{1}$, Christopher S. Blackman ${ }^{1}$ and Troy D. Manning ${ }^{2}$.

${ }^{1}$ Department of Chemistry, University College London, 20 Gordon Street, London, WC1H OAJ , United Kingdom

${ }^{2}$ Current address: Pilkington plc, Pilkington Technical Centre, Hall Lane, Lathom, Ormskirk, Lancashire, England, L40 5UF, United Kingdom

a i.p.parkin@ucl.ac.uk

received paper 20.11.2007, received revised paper 15.01.2008, accepted date 20.01.2008

Keywords: Solid state chemistry, Materials Science, Thin Films, Chemical Vapour Deposition, Thermochromism, Vanadium Dioxide.

\begin{abstract}
Thermochromic glazing is a type of intelligent glazing; one where the properties of the glazing change according to some external stimulus. More particularly a thermochromic window is a device that changes its transmission and reflectance properties at a critical temperature $\left(\mathrm{T}_{\mathrm{c}}\right)$. At this specific temperature the material undergoes a semi-conductor to metal transition. At temperatures lower than $\mathrm{T}_{\mathrm{c}}$ the window lets all of the solar energy that hits it through. At temperatures above $T_{c}$ the window reflects the infra-red portion of solar energy. In such a way thermochromic windows may help reduce air conditioning and heating costs leading to more energy efficient buildings. This review details the nature of the semi-conductor to metal transition and indicates how substitutional doping within a crystal lattice can be used to manipulate and fine tune the critical temperature. Also detailed is the underlying science and methodologies so far employed in the production of thermochromic thin films.
\end{abstract}


Solar control coatings.

The use of air-conditioning equipment in order to maintain comfortable conditions inside buildings during the summer months is ever increasing and consumes vast amounts of electricity [1]. There is a concurrent increase in carbon dioxide emissions and of various other atmospheric pollutants created during the power generation. The effect is a self propagating cycle: global warming increases necessitating the further use of air conditioning in the summer months leading to a further growth in carbon dioxide emissions. There is thus a requirement that this cycle is broken and carbon dioxide emissions limited.

Solar control coatings are a technology applicable to all types of glazing - commercial or residential, to play an active role in improving the energy efficiency of the building. The currently available products take an extreme approach to solar control. Current coatings consist of an all out approach that is applicable to constant climates. If an environment is consistently hot, tinted glass or thin metallic coatings can be used to reflect solar heat and prevent it from entering the building [2], limiting the need for internal cooling. In a consistently cold environment heat may be retained in a building by the use of a wavelength selective coating such as doped tin oxides such as ITO or K-glass; both of which are transparent in the visible part of the spectrum but highly reflective in the infra red [2]. This allows sunlight to enter into the building but prevents blackbody radiation and internally generated heat from escaping, consequently reducing heating requirements. [2]

However, coatings of either type typically produce only a marginal energy benefit in changeable climates such as northern and central Europe, the USA, Canada and Japan which have cold winters and hot summers. The use of thermochromic coatings [1-7], whose optical properties are dependant on temperature and are usually related to a structural phase change, may have potential application in these geographical areas.

Vanadium (IV) oxide is an example of a thermochromic material which shows great promise for use in glazing coatings. Figure 1 schematically indicates the manner in which thermochromic glazing coatings work.
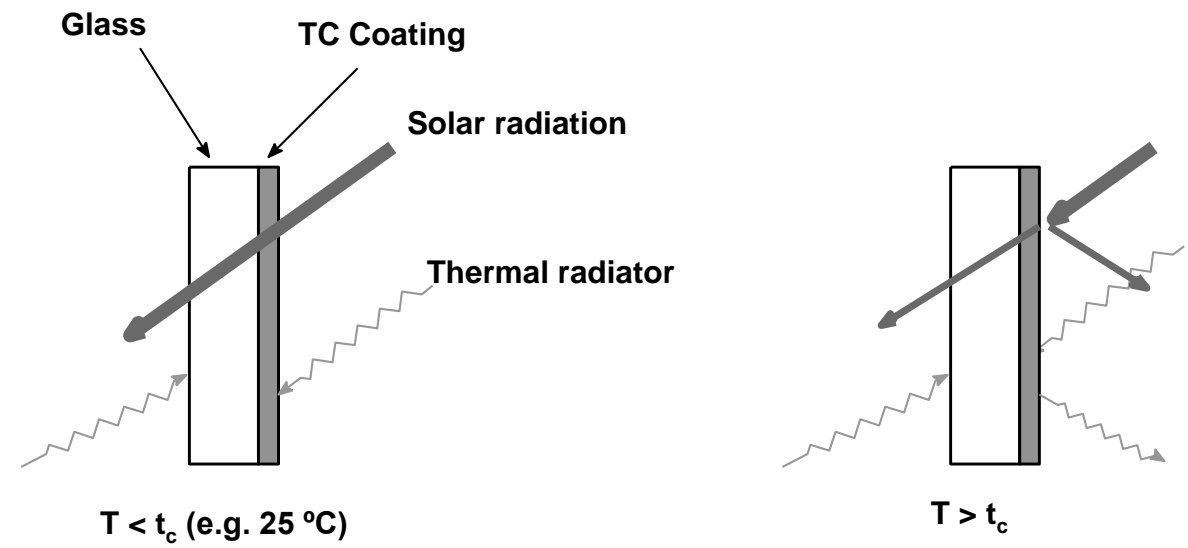

Figure 1 Schematic demonstration of the application of thermochromic materials to advanced window glazing [8].

The transition temperature $\left(\mathrm{T}_{\mathrm{c}}\right)$ for a pure single crystal of vanadium (IV) oxide is $68{ }^{\circ} \mathrm{C}$. At temperatures below $\mathrm{T}_{\mathrm{c}}$ the material is transparent in both the infra red and visible part of the spectrum, thus allowing solar radiation to pass through the window maximizing the heating effect of sunlight and black body radiation within the building. At temperatures above $T_{c}$ the coating is transparent in the visible but becomes reflective in the infra red part of the spectrum. This prevents the thermal part of solar radiation from heating the building interior. This also allows for the 
greatest use of natural light which is highly desirable as internal lighting contributes towards the buildings energy use and maintenance costs.

At $68{ }^{\circ} \mathrm{C}$ the critical temperature of vanadium (IV) oxide is too high to be effective in maintaining a comfortable temperature $\left(18-25^{\circ} \mathrm{C}\right)$. The use of dopants has been shown to affect the critical temperature. This may increase or decrease depending on factors such as dopant size [9], dopant charge [10] and changes in electron carrier density [11]. Tungsten has been shown to the most effective dopant to lower the Tc of vanadium (IV) oxide [9] with a 2 atom\% tungsten loading reducing Tc to around $25{ }^{\circ} \mathrm{C}$ in films prepared by physical vapour deposition [12] and sol-gel coating [13].

One significant challenge facing thermochromic coatings based on doped vanadium (IV) oxide is the balance of the extent of the transition and the visible transmittance. For larger changes in reflective properties visible transmission is low [12-15], this may require an increase in internal lighting, negating the energy benefit of having the coating in the first place. Two methods have been investigated to improve the visible transmittance of these films. Fluorine doping [4] into vanadium (IV) oxide thin films by r.f. sputtering formed films of $\mathrm{VO}_{\mathrm{x}} \mathrm{F}_{\mathrm{y}}$, transmittance properties were improved and also led to a decrease in $\mathrm{T}_{\mathrm{c}}$. Fluorine doping has however, also been reported [12] to decrease the sharpness of the thermochromic transition, potentially reducing their usefulness in glazing. A potentially more promising solution to this problem is the direct application of an antireflection coating to the thermochromic film. Silicon (IV) oxide over layers were found to greatly improve the visible transmittance below and above $T_{c}$ without affecting the temperature that $\mathrm{T}_{\mathrm{c}}$ occurs at [14]. Multifunctional window coatings have been prepared [15] using titanium (IV) oxide as and antireflection over layer. Improved transmittance and a reduced transition temperature were reported. It was proposed that such composite films would have multifunctional properties as titanium (IV) oxide is a well characterised photo-catalyst [16] that is used in self-cleaning glazing $[17,18]$.

To enable the use of vanadium (IV) oxide as an intelligent window coating, a method is required to produce thin films on glass cheaply and efficiently ideally during the manufacturing process in the float-glass furnace [19]. Physical vapour deposition and sol-gel methods are processes that require the glass to be ready formed and cannot be integrated directly into a float-glass furnace making them off-line processes. The ideal process for applying thin films of material to glass substrates is atmospheric pressure chemical vapour deposition which has the advantage of not requiring a reduced pressure environment and has the high growth rates necessary for a high throughput process.

The structure and properties of vanadium (IV) oxide.

Since the thermo-conductive properties of several transition metal oxides was investigated in the late 1950's [20], much research has been undertaken to comprehend the nature of this transition. The transition was originally named a metal-to-insulator transition due to the changes in conductive properties of the materials, but other properties of these materials soon became apparent and has since been re-labelled a metal-to-semiconductor transition (MST). Their optical properties also showed large decreases in transmittance and increases in reflectance on passing through the transition temperature [21, 22].

The most promising of the transition metal oxides investigated by Morin for technological applications is vanadium (IV) oxide as this material has a metal-to-semiconductor transition temperature of $68{ }^{\circ} \mathrm{C}$, the closest to room temperature of the thermo-transitive metal oxides. This metal-to-semiconductor phase transition (MST) corresponds to a structural phase transformation from monoclinic to tetragonal (Figure 2, ref 23). The low temperature, monoclinic phase has unit 
cell parameters $a=5.75 \AA, b=4.52 \AA, c=5.38 \AA$ and $\beta=122.60^{\circ}$. The structure involves $\mathrm{V}^{+}{ }_{-}$ $\mathrm{V}^{+}$pairing with alternate shorter $(0.265 \mathrm{~nm})$ and longer $(0.312 \mathrm{~nm}) \mathrm{V}^{+}-\mathrm{V}^{+}$distances along the monoclinic $a$ axis. The high temperature phase has a tetragonal rutile type structure, cell parameters $a=4.55 \AA$ and $c=2.85 \AA$, with equidistant vanadium atoms $(0.288 \mathrm{~nm})$ in chains of edge sharing [VO6] octahedra. On passing through the MST, the (100) planes of vanadium atoms in the monoclinic phase shift by $0.043 \mathrm{~nm}$ parallel to (001). This shift is sufficient to break the $\mathrm{V}^{+}-\mathrm{V}^{+}$ pairs to form a tetragonal phase allowing metallic conductivity [23]. Figure 2 shows representations of the two phases of vanadium (IV) oxide. The diagram of the monoclinic phase displays the alternate $\mathrm{V}^{+}-\mathrm{V}^{+}$pairs and the distortion of the vanadium atoms along the a-axis.

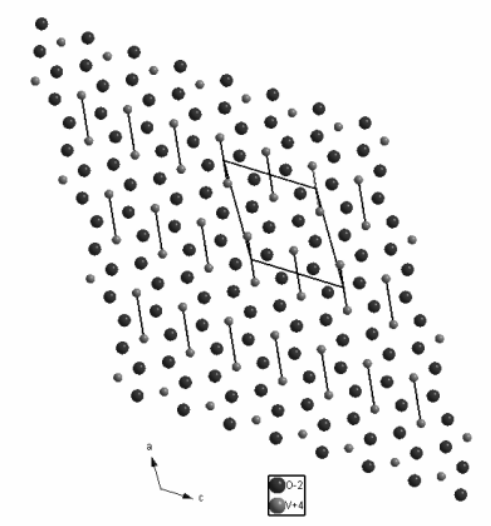

a

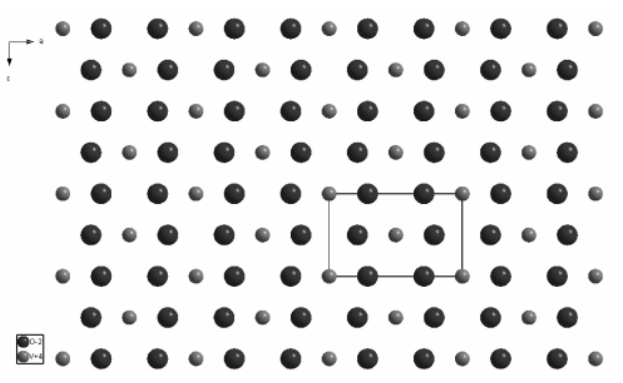

b

Figure 2. Representations of the structures of (a) monoclinic $\mathrm{VO}_{2}$, with $\mathrm{V}-\mathrm{V}$ pairs indicated, and (b) tetragonal $\mathrm{VO}_{2}$, viewed along the $b$-axis of the unit cell. Oxygen atoms are the larger dots.

On passing through the transition temperature, electrical conductivity and infrared reflectivity increase dramatically but there is virtually no change in the visible region. This has lead to vanadium (IV) oxide being investigated as a potential data storage media [1, 3], an optical switch [24], and as an infrared modulator for missile guidance systems [5]. It is as an intelligent window coatings that vanadium (IV) oxide may find its most beneficial application.

The nature of the metal-to-semiconductor transition in vanadium (IV) oxide.

A larger number of computational studies have been undertaken to investigate the details of the metal-to-semiconductor transitions in transition metal oxides and vanadium (IV) oxide in particular [25-30]. Despite these studies, the metal-to-semiconductor transition is still not completely understood. Goodenough [26], produced a useful explanation describing the band structure of the two phases of vanadium (IV) oxide in terms of molecular orbitals. 


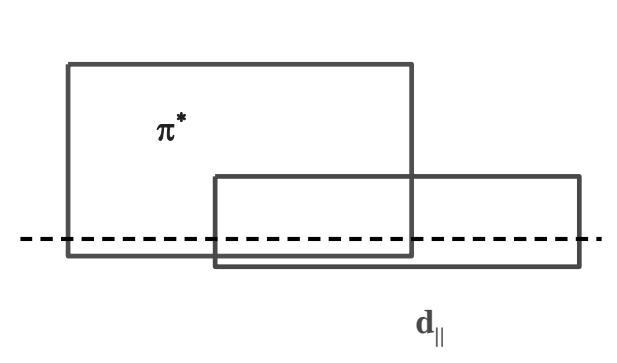

(a) Tetragonal

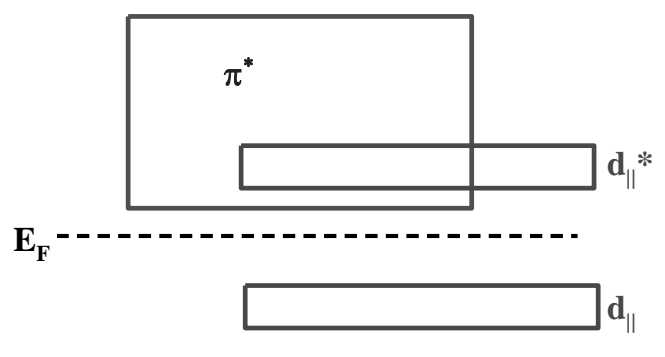

(b) Monoclinic

Figure 3. Band structure scheme for (a) tetragonal and (b) monoclinic $\mathrm{VO}_{2}$ at the Fermi level (EF) (adapted from Ref 29). d\| orbitals are due to $\mathrm{V}-\mathrm{V}$ pairs resulting from overlap of $\mathrm{dx} 2-\mathrm{y} 2$ atomic orbitals.

Goodenough discussed the possibility of an anti-ferroelectric transition being the driving force for the metal to semiconductor transition in vanadium (IV) oxide. He initially constructed an energy level diagram for tetragonal vanadium (IV) oxide (Figure $3 \mathrm{a}$ ) and then argued that V-V pairing becomes energetically stable on cooling after the rearrangement of the band structure in forming the monoclinic phase (Figure 3b). In this way, he argued that there are two transition temperatures, $\mathrm{T}_{\mathrm{c}}$ due to the anti-ferroelectric distortion and $\mathrm{T}_{\mathrm{c}}{ }^{\text {', }}$, due to the crystallographic distortion, which happen to be coincident for vanadium (IV) oxide. Goodenough concluded that the driving force for lowtemperature distortion in vanadium (IV) oxide is the anti-ferroelectric component of the distortion and that the transition temperature $\mathrm{T}_{\mathrm{c}}$ is controlled by the entropy of the lattice vibrational modes and not by the thermal excitation of electrons into the anti-bonding bands.

A more recent paper by Eyert [31], uses density functional theory and the local density approximation, corroborates Goodenough's model as a Peierls-like instability. The MST of vanadium (IV) oxide, when cycled between the low and high temperature phases, displays hysteresis behaviour. This indicates a first-order transition whereby some regions of the material have completed the transition and others have not. First-order transitions involve a latent heat and the energy of the transition cannot be instantaneously transferred between the material and the surroundings.

Doping of vanadium (IV) oxide.

The introduction of dopants at low levels may influence the temperature $\left(\mathrm{T}_{\mathrm{c}}\right)$ at which the metal-tosemiconductor transition occurs. The way dopants introduced into the vanadium (IV) oxide lattice give rise to this effect is less well understood than the nature of the metal to semiconductor itself. There are various theories on the action of doping in vanadium (IV) oxide that result from experiments and theoretical calculations.

It has been observed that high valence metal ions, such as tungsten (VI) or niobium (V), when doped into vanadium (IV) oxide, decrease the metal to semiconductor (MST) temperature of vanadium (IV) oxide, room temperature with 2 atom \% tungsten (VI). Low valence ions, such as aluminium (III) or chromium (III), were shown to increase the MST temperature. It has been observed that dopant ions with an ionic radius smaller than $\mathrm{V}^{4+}$, or that created $\mathrm{V}^{5+}$ defects (which were smaller than $\mathrm{V}^{4+}$ ) increased the MST temperature, while dopant ions with a larger ionic radius than $\mathrm{V}^{4+}$ caused a decrease in the MST temperature [9].

A more involved discussion (by Goodenough) builds on X-ray diffraction observations that a second semi-conducting phase is present in doped samples between the low-temperature monoclinic phase and the high-temperature tetragonal phase $[11,26]$. For low-valence dopant ions, this second semi-conducting phase has an orthorhombic structure and for high-valence ions it has a rutile 
structure. Goodenough then explains various scenarios of doped vanadium (IV) oxide in accordance to his description of the MST [26].

Cations that cannot contribute to homopolar bonds but can participate through $\pi$ bonding, such as titanium (IV) $\mathrm{d} 0$, decrease the crystallographic transition temperature $\mathrm{T}_{\mathrm{c}}{ }^{\prime}$. Dopants that introduce electrons to the vanadium $d$ bands, such as cations with a higher valence state than vanadium (IV) (e.g. tungsten (VI) or niobium (V)) or anions with a lower valence state than vanadium (IV) (such as $\mathrm{F}^{-}$), reduce the anti-ferroelectric stabilisation of the low-temperature phase by introducing $\pi^{*}$ electrons into the anti-ferroelectric state. This then reduces the anti-ferroelectric transition temperature, $\mathrm{T}_{\mathrm{c}}$. The additional electrons may be localised as discrete vanadium (III) ions.

Low valence cations, introduced into the vanadium(IV) oxide lattice stabilise the anti-ferroelectric distortion as they are relatively more stable in lower anion co-ordination sites, such as those in monoclinic vanadium(IV) oxide with its distorted lattice, than high valence cations,. Chromium (III) would be expected to show the smallest effect due to having a high preference for octahedral coordination.

The work of Goodenough has been further confirmed by Tang et al [32] who investigated the oxidation states of vanadium and tungsten in $\mathrm{W}_{0.05} \mathrm{~V}_{0.95} \mathrm{O}_{2}$ and $\mathrm{W}_{0.08} \mathrm{~V}_{0.92} \mathrm{O}_{2}$ by EXAFS and magnetic susceptibility studies. They suggest the formation of $\mathrm{V}^{3+}-\mathrm{W}^{6+}$ and $\mathrm{V}^{3+}-\mathrm{V}^{4+}$ pairs in vanadium (IV) oxide with tungsten doping, in accordance with Goodenough's theories on the stability of the anti-ferroelectric distortion.

Tungsten Doping.

Of the dopants investigated so far in single crystals and PVD or sol-gel prepared thin films, tungsten [33-38] has been found to reduce the transition temperature of vanadium (IV) oxide by the greatest extent per atom $\%$ and as such is the dopant that been the focus of the majority of research. For all reported methods of preparation, vanadium (IV) oxide films containing $\sim 2$ atom $\%$ tungsten have been shown to have a thermochromic transition temperature of about $25{ }^{\circ} \mathrm{C}$, suggested as the ideal transition temperature for intelligent window coatings.

Other Dopants.

In addition to tungsten, other metal ions, when introduced into the vanadium (IV) oxide lattice, have been shown to affect the metal-to-semiconductor transition temperature of vanadium (IV) oxide. The direction and magnitude of the change in the transition temperature is related to a number of factors such as dopant ion charge and size. Sol-gel methods for the formation of thin films of vanadium (IV) oxide have seen the greatest variety of dopant ions used with most of the first row transition metals having been used [37-40]. Other metal ions have also been doped into the vanadium (IV) oxide lattice by sol-gel methods, including gold [41], molybdenum [42], niobium [43], and aluminium [37]. The co-doping of molybdenum and tungsten, or tungsten and titanium into the vanadium (IV) oxide lattice has also been shown to give very low thermochromic transition temperatures. Tungsten and titanium co-doping of vanadium (IV) oxide displayed almost no hysteresis width for the infrared switching [44].

The range of metal ions that have been doped into the vanadium(IV) oxide lattice using PVD methods is not quite as extensive as those investigated with sol-gel and is mostly limited to those that are known to induce the largest decrease in the metal-to-semiconductor transition temperature, namely tungsten [12, 34, 35], and molybdenum [45-46]. Iron doping of vanadium (IV) oxide by PVD showed a minimum thermochromic transition temperature with 1.4 atom\% $\mathrm{Fe}$ at $59{ }^{\circ} \mathrm{C}$ on the heating cycle [10]. 
Vanadium (IV) oxide film doped with 1.2 atom\% fluorine (fluorine replacing oxygen atoms) has been shown to reduce $\mathrm{T}_{\mathrm{c}}$ to $20{ }^{\circ} \mathrm{C}$, but also causes the hysteresis width of the thermochromic transition to broaden appreciably making fluorine doping less suitable for use in window coatings [10]. The co-doping of tungsten and fluorine by PVD into vanadium (IV) oxide gave thin films with reduced thermochromic transition temperature and with improved visible transmittance over tungsten doped vanadium (IV) oxide [47].

Film stresses and their effect on the thermochromic transition of vanadium (IV) oxide.

Pure, crystalline vanadium (IV) oxide displays a metal-to-semiconductor transition at $68{ }^{\circ} \mathrm{C}$. Most thin films of the material also display the transition at the same or slightly reduced $\left(66{ }^{\circ} \mathrm{C}\right)$ temperature. There have been reports in the literature where very thin films (ca $200 \mathrm{~nm}$ ) of pure vanadium (IV) oxide grown by various methods have shown transition temperatures lower than 68 ${ }^{\circ} \mathrm{C} .[41,48,49]$ Maruyama et al [47] link the variations in the thermochromic transition temperature to the thickness of the thin film, but does not suggest a mechanism for the effect, and indeed closer inspection of their data suggests that this is not a reasonable conclusion. Case [49] however, investigates the effects of mismatches in substrate-film expansion co-efficients that cause extrinsic stresses in the film crystallites. Low-energy ion bombardment is utilised to cause intrinsic stresses in the thin film. Both effects are shown to decrease the temperature at which the MST occurs. Rakotoniaina et al [50] also discuss the effects of strain on the MST of vanadium (IV) oxide caused by pressure and tungsten doping, showing that stress along the square plane of the rutile cell can result in a decrease in the thermochromic transition temperature.

\section{Methods of preparing pure and doped vanadium (IV) oxide films.}

Single crystals of vanadium (IV) oxide are unsuitable for many of the technological applications mentioned and thin films of the material are required. Thin films also survive the stresses resulting from cycling between the two polymorphs of vanadium (IV) oxide involved in the MST, which causes single crystals to crack and disintegrate after only a small number of cycles [9]. Guzman et al [51] showed that a vanadium (IV) oxide thin film prepared by sol-gel methods could be cycled 108 times without any degradation in electrical contrast. The preparation of vanadium (IV) oxide thin films has preceded using three routes, sol-gel spin and dip coating; physical vapour deposition (PVD) and chemical vapour deposition (CVD). Of these CVD has attracted less interest due to the inherent difficulty in achieving controllable stoichiometry using this method and the relatively few volatile precursors available. Thin films of vanadium (IV) oxide prepared by PVD methods are generally used for fundamental studies of the properties of the thin films, whereas sol-gel spin or dip coated takes a more application based approach. Chemical vapour deposition studies also fall into the latter category as this methodology has the most potential for large scale industrial process integration. Preparation of thin films of vanadium (IV) oxide for commercial applications is often the focus of the research.

The sol-gel method.

The sol-gel method involves the formation of thin films by dip or spin coating substrates with solutions of metal alkoxides, and then suitably treating them to form a thin film of the required metal oxide. The sol-gel methods are thus multi-stage, off-line processes. For the formation of vanadium (IV) oxide this involves partially hydrolysing the initial coating and then heating it in a reducing atmosphere to form crystalline vanadium (IV) oxide. Dopants are readily introduced by the addition of salts or additional alkoxides to the precursor solution in the necessary proportions. Due to the simplistic nature of the method, sol-gel has been used extensively to prepare vanadium (IV) oxide thin films in a pure and doped form. The most widely used precursors for the sol-gel preparation of vanadium (IV) oxide are vanadyl tri(iso-propoxide) and vanadyl tri(tert-amyloxide). 
The alkoxide is dissolved in a parent alcohol to form the sol. Different alcohols cause different transesterifications reactions and the formation of different alkoxides. The whole of the first row dblock elements and much of the second and third row d-block elements have been doped into vanadium (IV) oxide using this method.

A new method using polyvanadate sols was reported by Takahashi et al [38] that used metallic vanadium dissolved in $30 \% \mathrm{H}_{2} \mathrm{O}_{2}$ and then heated to form a hydrosol. The hydrosol could then be spin coated onto a suitable substrate and reduced in a hydrogen atmosphere. Tungsten and molybdenum could be introduced in metallic form at the initial dissolution stage [38, 44].

Physical vapour deposition methods.

The second general method discussed here involves physical vapour deposition (PVD) techniques [52]. These involve energetically removing atoms or molecules from a target under reduced pressure conditions. The species can then react with any seed gases present in the deposition chamber to form a thin film of the desired compound by condensing onto a substrate. The composition of the thin film can be accurately controlled by the amount of material removed from the target and the amount of reactive gas present in the deposition chamber. There are numerous ways to energetically remove atoms from a metal target and most have been used to prepare vanadium (IV) oxide thin films. These include laser ablation, RF magnetron sputtering, DC magnetron sputtering and ion beam sputtering. Doping is also readily achieved by placing another target in the deposition chamber. The amount of doping can be easily controlled by the relative sizes of the targets.

Chemical vapour deposition methods.

The final method used to prepare thin films of $\mathrm{VO}_{2}$ is chemical vapour deposition. In particular APCVD is the ideal method for producing thin films on high throughput glass substrates.

Doped vanadium (IV) oxide thin films prepared by CVD methods have to our knowledge and prior to our work not been reported in the literature. Pure vanadium (IV) oxide films have been produced by chemical vapour deposition onto glass substrates [43]. Vanadyl tri(iso-propoxide) or vanadyl tri(iso-butoxide) [53] have been used as single source precursors for the CVD of vanadium(IV) oxide films, usually by reducing the resultant vanadium(V) oxide thin films. Vanadium oxides can also be deposited using $\mathrm{VCl}_{4}$ or $\mathrm{VOCl}_{3}$ and an oxygen source such as water or ethanol [54] or with carbon dioxide [55]. These films can then be reduced to vanadium (IV) oxide in a suitable atmosphere. Vanadium (IV) oxide thin films have also been prepared from vanadium(III) acetylacetonate, [V(acac $)_{3}$ ], by an APCVD method followed by slow post-deposition cooling [48], and from vanadium(IV) acetylacetonate, [V(acac $\left.)_{4}\right]$, by a pyrolysis method in a controlled atmosphere [56]. Vanadyl acetylacetonate, $\left[\mathrm{VO}(\mathrm{acac})_{2}\right]$, has been used to prepare the meta-stable $\mathrm{VO}_{2}(\mathrm{~B})$, which can be converted to the tetragonal phase by annealing in argon at $500{ }^{\circ} \mathrm{C}$ [57-58]. Vanadyl precursors have also been used in a CVD method to prepare various vanadium oxide thin films including vanadium (IV) oxide [59]. The precursors used in these studies are generally expensive and require a post-deposition reduction process to form vanadium (IV) oxide thin films. Ideally a process is required that utilises inexpensive, readily available precursors that will produce vanadium (IV) oxide directly without the need for a reduction step.

Comparison of the different production methods.

Sol-gel methods are simple to use, with readily available, though expensive precursors and give films with complete coverage of the substrate and reasonably even thickness. They are not, however, suitable for integrating into the industrial float-glass process as sol-gel techniques often involve spin coating the substrate, a process that is difficult with very large areas of glass. 
PVD methods require reduced pressure or vacuum conditions and expensive evaporation/sputtering/ablation equipment. This would increase production costs, limiting the commercial applications due to economic factors. Growth rates are also often low with PVD techniques making them additionally unsuitable for integration into modern float glass processes.

Glass manufacturers currently use sol-gel and PVD methods to prepare coated-glass products but the extra cost of these off-line processes can often make them prohibitively expensive for widespread, consumer use.

Atmospheric pressure CVD equipment can be easily integrated into the float-glass production process, the coaters are easily constructed and no expensive vacuum systems are required. The precursors are often readily available and relatively inexpensive, especially when films of only a few hundred nanometers may be required. Growth rates are also high compared to PVD techniques and are sufficiently fast to be suitable for float-glass production lines. These factors make APCVD methods the most attractive when wishing to prepare coated float-glass; indeed APCVD finds use in the production of $\mathrm{K}$ glass and Activ [19].

Atmospheric pressure chemical vapour deposition.

Chemical vapour deposition (CVD) is a process whereby a thin solid film is synthesized from a gaseous phase by a chemical reaction. It is this reactive process that distinguishes CVD from a physical vapour deposition processes. The APCVD process is shown schematically in figure 4 . There are several steps associated with the CVD process (not always in this order [60])

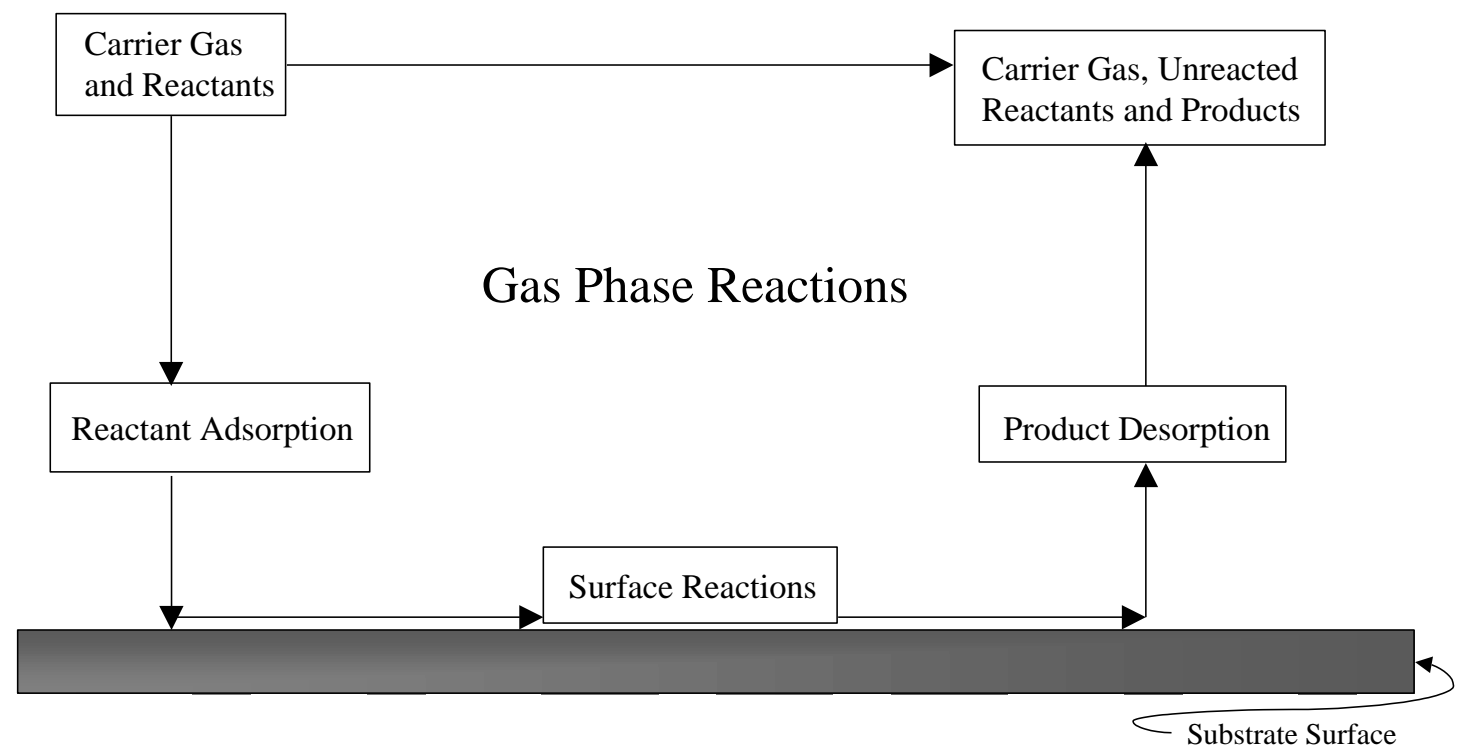

Figure 4. Schematic representation of the atmospheric pressure chemical vapour deposition process.

Transport of the reactive species to the reaction site.

Gas phase reaction.

Adsorption onto the substrate surface

Nucleation on the substrate surface / Surface reaction 


\section{Reaction and desorption of by-products}

Film growth.

In the APCVD experiment the reaction chamber is at or close to atmospheric pressure. The precursors therefore need to be low-melting solids or volatile liquids and are transported to the reaction site via hot, inert carrier gas. At the very least, precursors must have enough vapour pressure to allow sufficient material to transport to the reaction chamber in the gas phase. The substrate temperature also needs to be relatively high to initiate the deposition.

Reaction sites in the APCVD process.

In the reaction chamber two types of reaction may occur; homogeneous reactions occurring entirely in the vapour phase and heterogeneous reactions that occur at the vapour - solid surface interface [61]. In cold wall reactors such as those used at UCL the homogeneous reactions and heterogeneous reactions at the reactor walls are suppressed due to the lower heat input to the system. Vapour substrate reactions are therefore dominant [61]. Little is known about these types of reaction due to the difficulties in determining the exact nature of the surface species and the influence of the electronic structure of the solid surface on the kinetics of the reaction.

Recent work conducted using APCVD.

Four precursor systems have received the most attention in the preparation of thin films of tungsten doped vanadium (IV) oxide via APCVD [62-64]. Some work has been conducted using aerosol assisted chemical vapour deposition (AACVD) to produce thin films of tungsten or niobium doped vanadium (IV) oxide [68, 69, 71].

\section{APCVD}

The four precursor systems used in APCVD were:

A) $\mathrm{VCl}_{4}+\mathrm{W}(\mathrm{OEt})_{6}+\mathrm{H}_{2} \mathrm{O}$ deposition at $600{ }^{\circ} \mathrm{C}$

B) $\mathrm{VOCl}_{3}+\mathrm{WCl}_{6}+\mathrm{H}_{2} \mathrm{O}$ deposition at $650{ }^{\circ} \mathrm{C}$

C) $\mathrm{VCl}_{4}+\mathrm{WCl}_{6}+\mathrm{H}_{2} \mathrm{O}$ deposition at $550^{\circ} \mathrm{C}$

D) $\mathrm{VO}(\mathrm{acac})_{2}+\mathrm{WCl}_{6}+2 \% \mathrm{O}_{2}$ in $\mathrm{N}_{2}$ deposition at $525^{\circ} \mathrm{C}$

The four precursor systems will be referred to as A, B, C or D accordingly.

\section{Physical Properties.}

Films deposited from APCVD reactions A and B were similar in appearance to un-doped vanadium (IV) oxide being a dark yellow / brown in colour, they were opaque in appearance. The majority of films had poor adhesion qualities; they could be scratched with a brass stylus and wiped off with a tissue. However, the majority did pass the Scotch tape test. Films deposited from the APCVD reactions $\mathrm{C}$ and $\mathrm{D}$ were also similar in appearance to un-doped vanadium (IV) oxide being a dark yellow / brown colour in transmission. They however differed with a blue / silver colour in reflection; they appeared transparent and quite glassy in appearance. All of these films had better adhesion qualities; they could not be scratched with a brass stylus or wiped off with a tissue and all of the films passed the Scotch tape test.

X-ray diffraction (XRD) was used to characterise the films from all reactions and indicated the production of monoclinic vanadium (IV) oxide in all cases (Figure 5). As can be seen in the figure, in all cases the 011 reflection is the strongest. X-ray photoelectron spectroscopy (XPS) and energy 
dispersive analysis of X-rays (EDAX) were conducted to evaluate the tungsten dopant level present in all of the films. The two methods gave consistent results and indicated it was possible to introduce up to 1.2 atom \% into the vanadium (IV) oxide lattice from the APCVD reaction A; 3.5 or 3.0 atom $\%$ in sample from APCVD reactions B and D respectively, and up to 8 atom $\%$ in samples prepared from APCVD reaction $\mathrm{C}$. Because $\left[\mathrm{W}(\mathrm{OEt})_{6}\right]$ is a solid it has a relatively low vapour pressure and it was difficult to incorporate more than about one atom \% into the vanadium (IV) oxide matrix as seen with samples prepared from APCVD reaction A. Using higher bubbler temperatures or higher flow rates led to condensation problems in the CVD rigs gas lines and ultimately blockages. $\left[\mathrm{WCl}_{6}\right]$ is a solid but has better vapour pressure and vapour transport characteristics (less condensation and less blockages) than $\left[\mathrm{W}(\mathrm{OEt})_{6}\right]$ and correspondingly a higher $\mathrm{W}$ atom $\%$ was incorporated into the vanadium (IV) oxide matrix as seen in samples prepared from the APCVD reactions of $\mathrm{B}, \mathrm{C}$ and $\mathrm{D}$. Additionally the range of temperatures at which this precursor can be used at is wider allowing for a greater level of control. Subsequently $\left[\mathrm{WCl}_{6}\right]$ is preferred as a tungsten precursor.
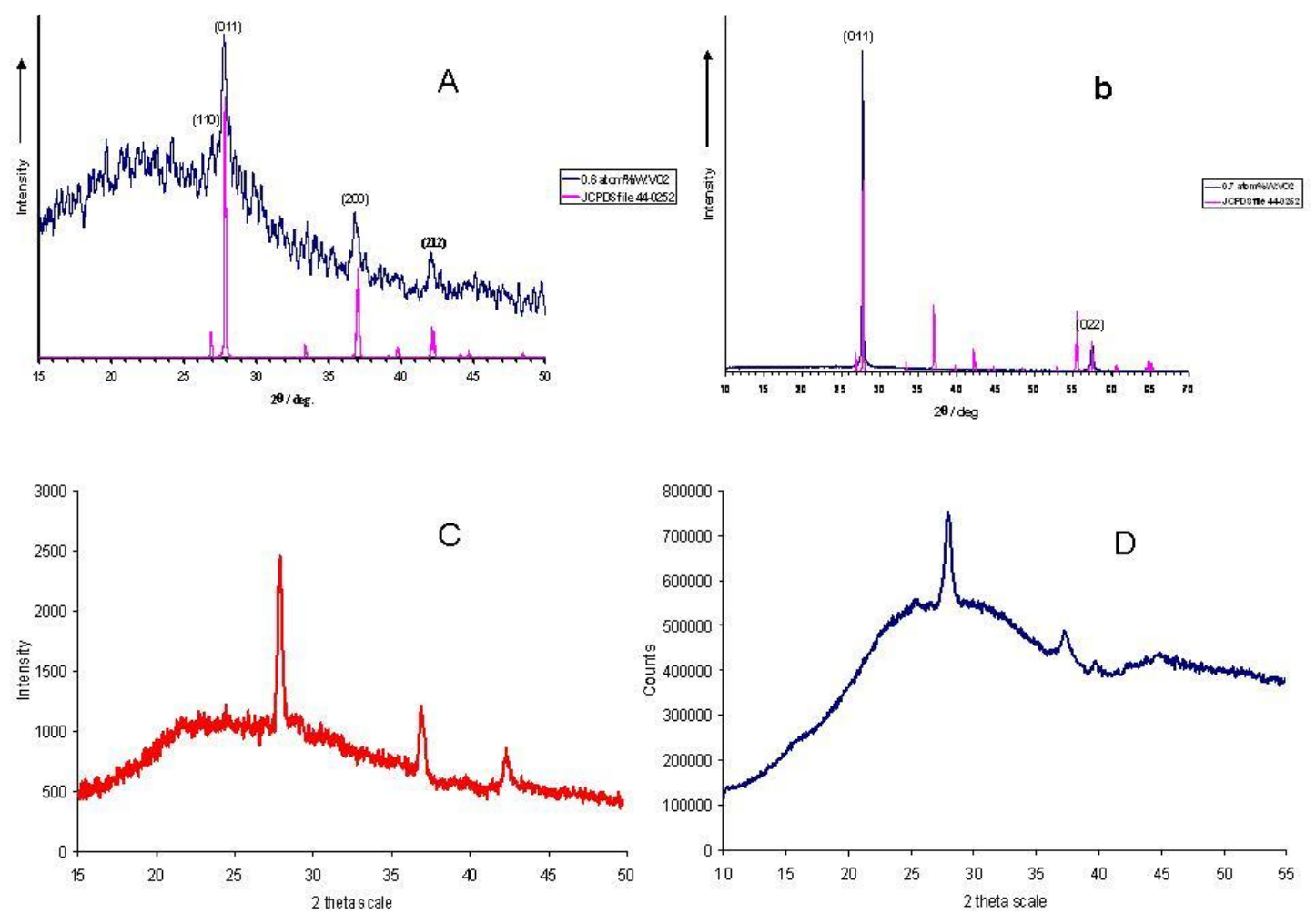

Figure 5. X-ray diffraction patterns of films made from APCVD reactions A, B, C and D. In all cases the 011 peak is dominant indicating preferred orientation with this plane. Some amorphous character due to the glass substrate is observed in C and D as these films are particularly thin (100$150 \mathrm{~nm})$.

Electron microscopy (plan view and side on view) was used to evaluate the surface morphology, film thickness and growth mechanism in each of these reactions. Films prepared from the APCVD reactions $\mathrm{A}$ and $\mathrm{D}$ had similar morphologies (figure 6A and 6D) of agglomerated particles on the substrate surface. Typically particles were $100 \mathrm{~nm}$ in diameter. Side on view micrographs (figure 7A and 7D) indicated a high degree of columnar growth. Both observations are consistent with a Volmer-Webber type island growth mechanism, typical of highly nucleating substrates. 


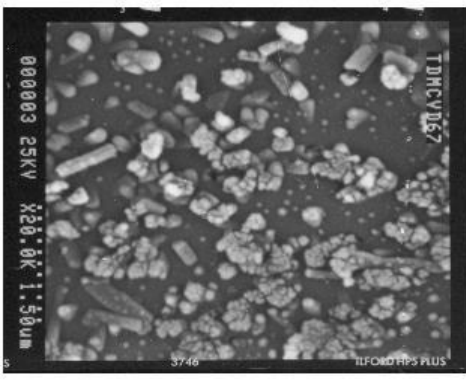

A

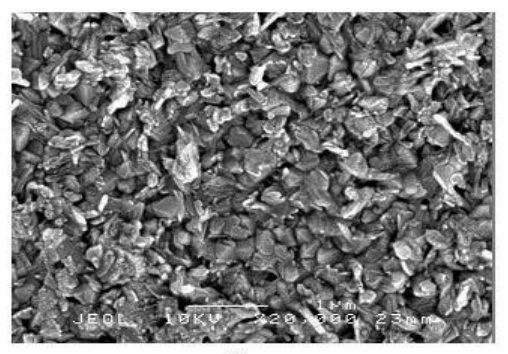

C

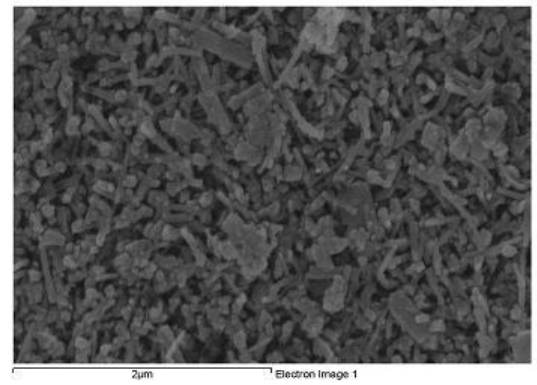

B

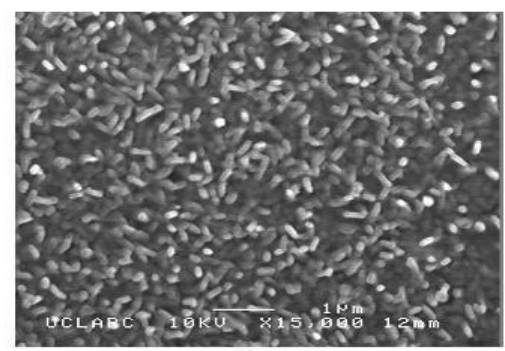

D

Figure 6. Plan view electron micrographs of thin films prepared from APCVD reactions A, B, C and D.

Films prepared from the APCVD reaction $\mathrm{B}$ and $\mathrm{C}$ were somewhat different. The surface was covered with thin worm like structures with a width of around $10 \mathrm{~nm}$ and lengths between 100 and $800 \mathrm{~nm}$ (figure 6B and 6C, and 7B and 7C respectively), almost perpendicular to the substrate. This is an unusual morphology and is an extreme form of the Volmer-Webber island growth mechanism.

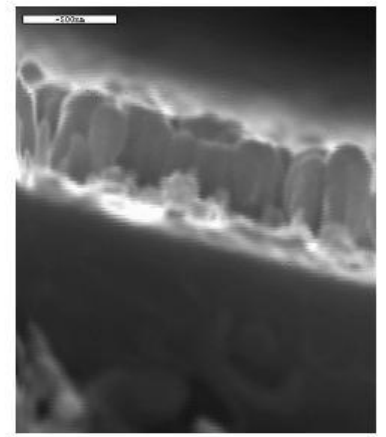

A

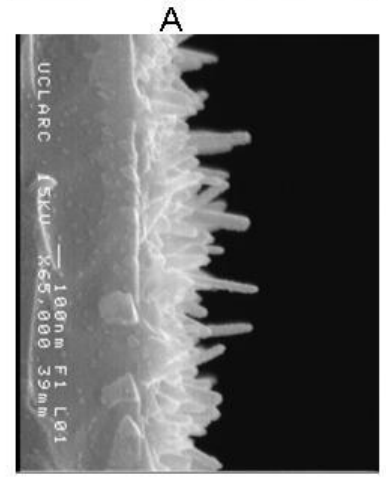

C

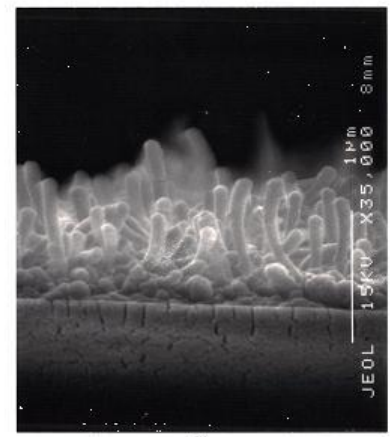

B

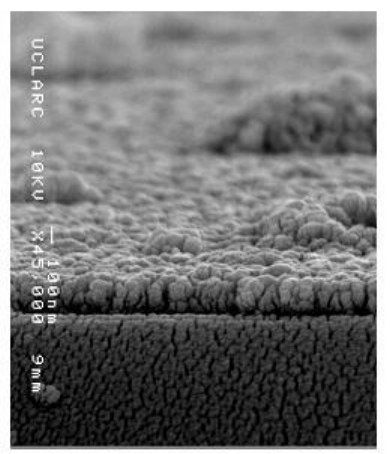

$\mathrm{D}$

Figure 7. Side view electron micrographs of thin films prepared from APCVD reactions A, B, C and D. 
Film thickness and growth rates are summarised in Table 1. As is expected films grown from the metal chloride precursors have faster growth rates than those from [VO(acac $\left.)_{2}\right]$.

Table 1. Table indicating film thickness and nominal growth rates.

\begin{tabular}{|l|l|l|l|}
\hline Reaction & Thickness / nm & $\begin{array}{l}\text { Deposition Time / } \\
\text { minutes }\end{array}$ & $\begin{array}{l}\text { Nominal Growth } \\
\text { Rate / nm.min }\end{array}$ \\
\hline A & $400-500$ & 1 & 450 \\
\hline B & $100-800$ & 1 & 400 \\
\hline C & $100-300$ & 1 & 200 \\
\hline $\mathrm{D}$ & $100-120$ & 3 & 35 \\
\hline
\end{tabular}

\section{Thermochromic properties.}

The thermochromic properties of these films were assessed by measuring the optical properties (transmission and reflectance spectroscopy and hysteresis at $2500 \mathrm{~nm}$ ) of the films above and below the transition temperature.

To give an indication of the effectiveness of the tungsten doped vanadium (IV) oxide thin films as intelligent window coatings the transmittance and reflectance spectra of the films were measured below and above the metal-to-semiconductor transition. In all cases when the temperature of the films was increased there was no appreciable change in the transmittance in the visible region but a dramatic change in the near infrared region was observed (figure 8). The same is true to a lesser extent with reflectance behaviour.
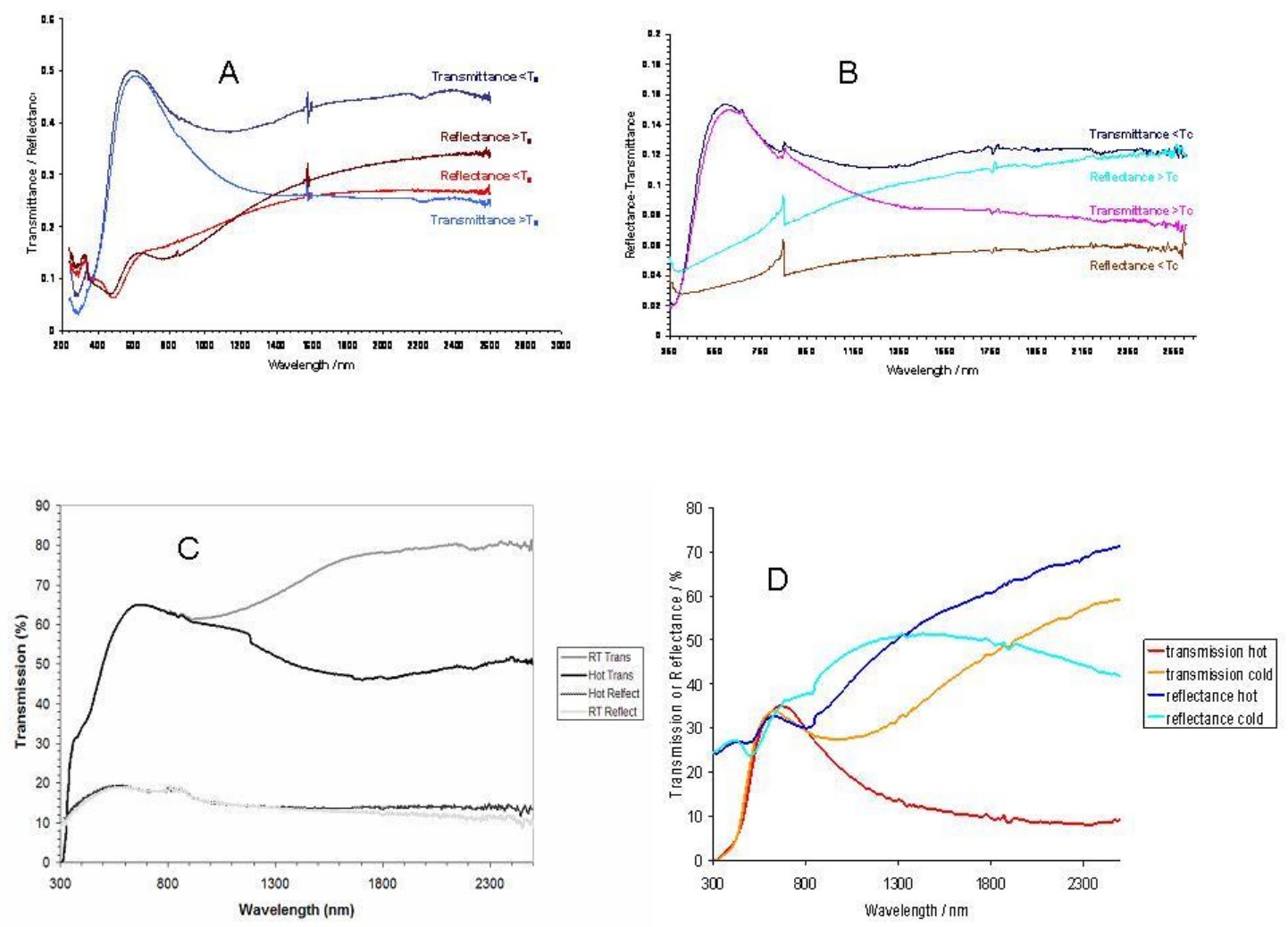

Figure 8. Transmission and reflectance spectra of typical films produced from the APCVD reactions $\mathrm{A}, \mathrm{B}, \mathrm{C}$ and $\mathrm{D}$. In all cases there is a large change in transmission at $2500 \mathrm{~nm}$ on undergoing the transition, ideal behaviour for an intelligent thermochromic window product. 
Films prepared from APCVD reaction B seem to be anomalous in that there is a small change (1\%) in the visible part of the reflectance spectrum upon heating. It is likely that this results from the greater film thickness of this sample. This is the desired behaviour for an intelligent window material. The extent of the transition $(\Delta \mathrm{T}$ and $\Delta \mathrm{R})$ at $2500 \mathrm{~nm}$ is given in table 2 .

Table 2. Table showing a summary of changes in transmission and reflectance at $2500 \mathrm{~nm}$ on undergoing the transition for typical films made from the APCVD reactions A, B, C and D.

\begin{tabular}{|l|l|l|}
\hline Reaction & $\Delta \mathrm{T} / \%$ at $2500 \mathrm{~nm}$ & $\Delta \mathrm{R} / \%$ at $2500 \mathrm{~nm}$ \\
\hline A & 20 & 8 \\
\hline B & 5 & 6 \\
\hline C & 32 & 3 \\
\hline D & 50 & 25 \\
\hline
\end{tabular}

As anticipated, thinner films have higher transmittance in the visible part of the spectrum and show a larger change on moving through the transition temperature. Ideally a glazing product will have a visible transmittance of at least $55 \%$ [59].

To determine the thermochromic transition switching temperature, the transmittance of the films at $2500 \mathrm{~nm}$ was measured while the temperature was cycled through the metal-to-semiconductor transition. The results of some of these measurements are shown in figure 9.
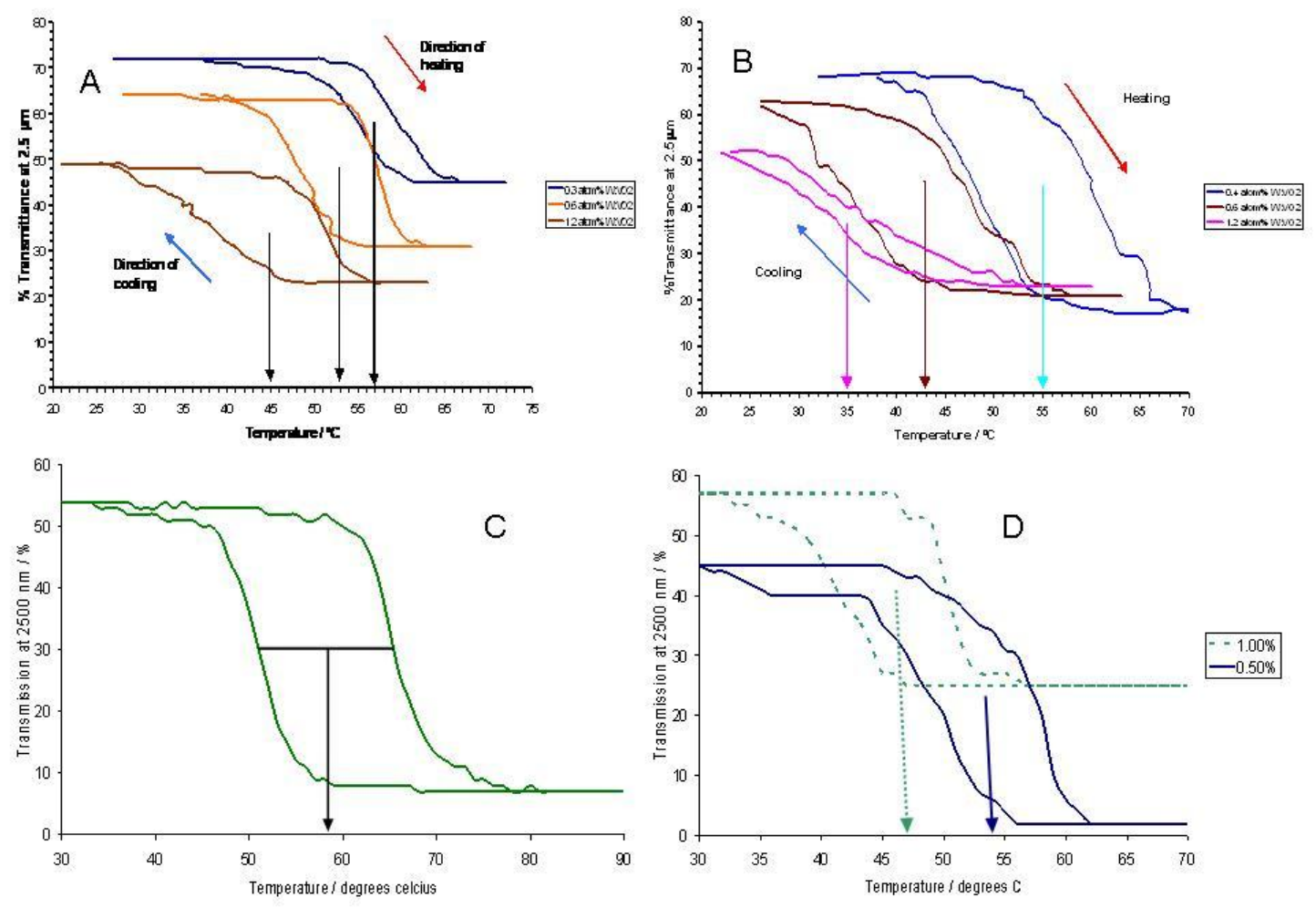

Figure 9. Hysteresis loops of typical films prepared from the APCVD reactions A, B, C and D.

In all cases, as the temperature was increased and the thermochromic transition temperature was approached, the transmittance of the films decreased dramatically. The thermochromic transition temperature decreased to as low as $45{ }^{\circ} \mathrm{C}$ for a vanadium (IV) oxide thin film doped with approximately 1-atom \% tungsten (prepared from APCVD reaction A). As the amount of tungsten in the films increased the hysteresis width was also found to increase, possibly due to a greater number of defects in the vanadium (IV) oxide lattice which would cause a greater variation in the 
temperatures at which different regions of the film would undergo the transition. In all cases the hysteresis width was found to be between 10 and $12{ }^{\circ} \mathrm{C}$. Ideally this would be as small as possible to maximise the energy benefit of having this type of thermochromic coating.

\section{Comparison of APCVD reactions.}

In all cases the films show promise as intelligent window coatings with reduced transition temperatures and the typical change in optical properties associated with un-doped vanadium (IV) oxide. In all cases thermochromic behaviour and the associated optical properties were maintained after repeated heating and cooling cycles.

AACVD of $\mathrm{VO}(\mathrm{acac})_{2}+\mathrm{W}(\mathrm{OEt})_{6}$.

In Aerosol Assisted Chemical Vapour Deposition (AACVD) the precursor is dissolved into a suitable solvent and then an aerosol is generated ultrasonically. A flow of inert gas, generally $\mathrm{N}_{2}$, transports the aerosol droplets to the deposition substrate, where the deposition takes place.

An advantage of AACVD is that the precursor does not need to be volatile (as in APCVD) but just soluble in the solvent; this allows the use of more unconventional precursors not usable with APCVD [65,66]. The solvent used, however, must have the right physical and chemical properties to form an aerosol [67]. Another advantage of AACVD is that it is easier to use when more than one precursor is used, for instance for the deposition of doped films. In fact it is simpler to control the precursor proportions in the solution than in the gas phase.

\section{Undoped $\mathrm{VO}_{2}$}

To our knowledge, AACVD has never been employed before to deposit $\mathrm{VO}_{2}(\mathrm{M})$ thin films. For this reason, a series of depositions was carried out to optimise the experimental conditions for the deposition of $\mathrm{VO}_{2}(\mathrm{M})$ only, with no other vanadium oxide phase present.

It was shown that experimental parameters such as the vanadium precursor, the nature of the solvent and the carrier gas flow rate affected the nature of the deposited phase [68]. The optimised conditions subsequently used to deposit doped $\mathrm{VO}_{2}$ are listed in table 3 .

Table 3. Experimental conditions for the deposition of $\mathrm{VO}_{2}(\mathrm{M})$.

\begin{tabular}{|l|l|}
\hline Vanadium precursor & $\mathrm{VO}(\mathrm{acac})_{2}$ \\
\hline Precursor concentration & $0.075 \mathrm{~mol} \mathrm{~L}^{-1}$ \\
\hline Solvent & Ethanol \\
\hline $\mathrm{N}_{2}$ flow rate & $1.5 \mathrm{~L} \mathrm{~min}^{-1}$ \\
\hline Temperature & $500-550^{\circ} \mathrm{C}$ \\
\hline Substrate & $\mathrm{SiO}_{2}$ coated glass \\
\hline
\end{tabular}

The deposited $\mathrm{VO}_{2}$ thin films had good optical properties and a transition temperature of about $58^{\circ} \mathrm{C}$; this value is about $10^{\circ} \mathrm{C}$ lower than what has been previously reported for single crystals, most likely due to strain in the coating lattice.

$\mathrm{W}$-doped $\mathrm{VO}_{2}$

The first metal employed as dopant was tungsten; in fact, as mentioned previously, tungsten proved to be the most effective metal to decrease the value of the transition temperature $\mathrm{T}_{\mathrm{c}}$ [33-38]. $\mathrm{W}\left(\mathrm{OC}_{2} \mathrm{H}_{5}\right)_{5}$ was used as tungsten precursor, dissolved in ethanol together with $\mathrm{VO}(\mathrm{acac})_{2}$; several 
depositions were carried out using different tungsten concentrations, to study the effect of the tungsten concentration on the transition temperature [69].

The deposition solutions used had a W/V atom ratio between 1 and $6 \%$; EDAX measurements of the deposited thin films showed that about one third of the tungsten of the solution was incorporated into the coatings. A good linear correlation was observed between the W/V ratio in solution and in the deposited films.

The coatings were analysed with different techniques such as XRD and Raman spectroscopy; both showed the presence of $\mathrm{VO}_{2}(\mathrm{M})$ phase only, with no $\mathrm{W}$ and/or $\mathrm{V}-\mathrm{W}$ mixed phases. This indicates the formation of a solid solution between tungsten and vanadium oxide, with no phase separation.

An example of the optical properties of $\mathrm{W}$-doped $\mathrm{VO}_{2}$ thin films is shown in Figure 10, where the transmittance and reflectance are reported at different temperatures - below and above the transition temperature. It can be seen how the behaviour is that expected from an intelligent window material: in fact the transmittance decreases while the reflectance increases for values of $\mathrm{T}$ above the transition temperature $T_{c}$ (Figure 10a and $10 \mathrm{~b}$ respectively).
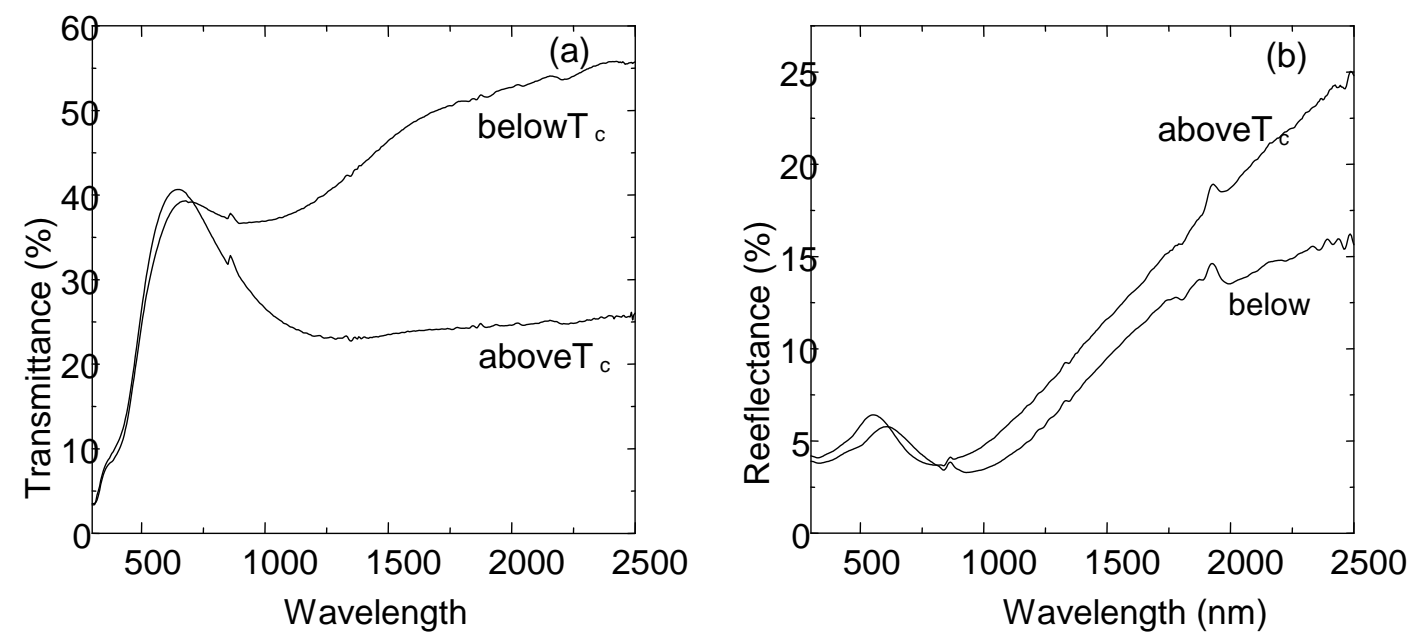

Figure 10. Transmission and reflectance spectra of a typical tungsten doped monoclinic vanadium (IV) ocide thin film produced via AACVD.

Figure 11 shows a comparison of the transition temperature for an un-doped and a W-doped $\mathrm{VO}_{2}$ coatings. The temperature was determined by measuring the change in the transmittance at $2500 \mathrm{~nm}$ as a function of the temperature. It can be seen that for the $\mathrm{W}$-doped sample there is a net decrease in the $\mathrm{T}_{\mathrm{c}}$ value; furthermore, the width of the hysteresis loop is smaller, making the material even more suitable for an intelligent material coating. 


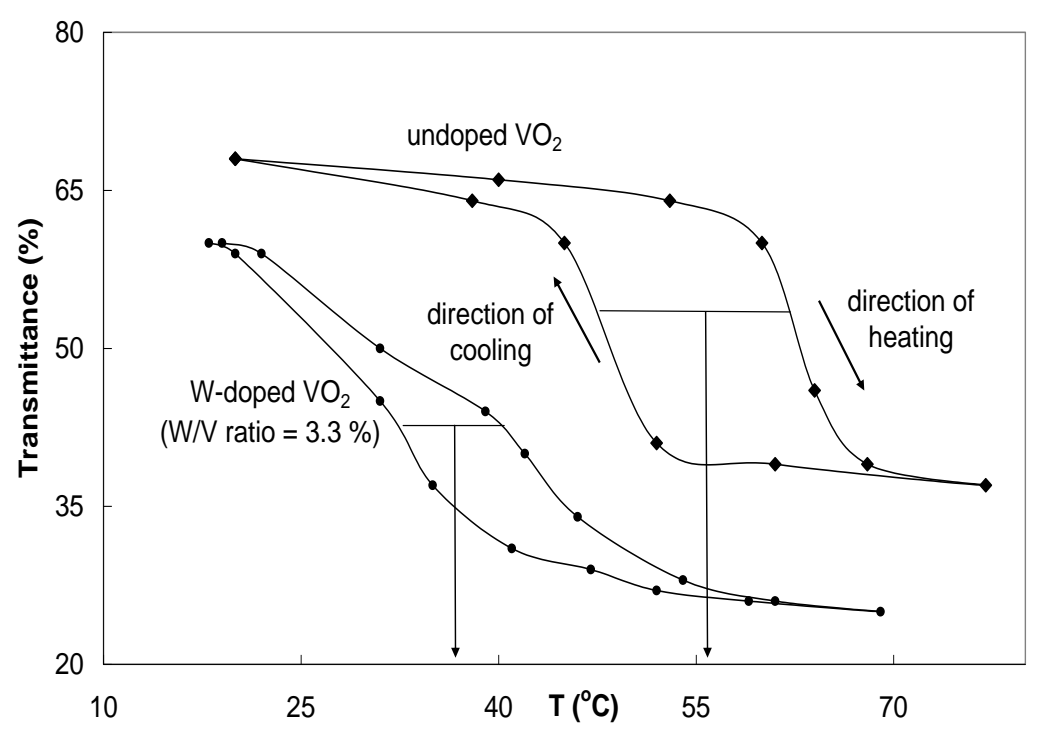

Figure 11. Hysteresis behaviour of thin films of doped and un-doped vanadium (IV) oxide prepared by AACVD.

The transition temperature was determined for every sample; these measurements showed a linear correlation between the tungsten amount in the film and the $T_{c}$ value. It was seen that an amount of dopant of $1 \%$ reduces the transition temperature of about $22^{\circ} \mathrm{C}$; therefore thin films with a concentration of about $2 \%$ have a $\mathrm{T}_{\mathrm{c}}$ value close to room temperature $\left(28^{\circ} \mathrm{C}\right)$.

$\mathrm{Nb}$-doped $\mathrm{VO}_{2}$

The use of niobium as dopant was considered as well; in fact, previous results obtained with APCVD methodology showed that $\mathrm{Nb}$-doped $\mathrm{VO}_{2}$ samples have a remarkable decrease in the transmittance in the infrared region, fulfilling the requirement for intelligent window coatings [70]. There were, however, difficulties to incorporate high concentration of niobium into the $\mathrm{VO}_{2}$ lattice; consequently the observed $\mathrm{T}_{\mathrm{c}}$ values were not close enough to room temperature.

In recent work, $\left[\mathrm{Nb}\left(\mathrm{OC}_{2} \mathrm{H}_{5}\right)_{5}\right]$ was used as niobium precursor, following the same experiemtnal procedure described above for tungsten. The $\mathrm{Nb} / \mathrm{V}$ molar ratio in the films, measured by EDAX analysis, reached values up to about $3.7 \%$ [71]; these concentrations are much higher than the ones obtained by APCVD $(0.4 \%)$, confirming the suitability of AACVD for the deposition of doped thin films.

However, differently from what was observed with tungsten, the correlation between the solutions and film concentrations was not linear; in fact a progressive increase was observed for the $\mathrm{Nb} / \mathrm{V}$ ratio in the films, until when a plateau was reached. These results confirm the difficulties of incorporating niobium into $\mathrm{VO}_{2}$ films, as previously experienced by APCVD.

The characterisation of these films showed that only $\mathrm{VO}_{2}(\mathrm{M})$ was present, with no $\mathrm{Nb}-\mathrm{V}$ mixed phases; the optical properties such as transmittance and reflectance showed features similar to the ones of $\mathrm{W}$-doped $\mathrm{VO}_{2}$ and reported in Figure 2.

A linear decrease in the transition temperature with increasing niobium concentration was observed as well, indicating the effect of niobium as dopant. However, a niobium concentration of about $2 \%$ lowered the value of $\mathrm{T}_{\mathrm{c}}$ of about $15^{\circ} \mathrm{C}$; therefore it can be stated that niobium is less effective if compared with tungsten. However, it is still possible to reach $\mathrm{T}_{\mathrm{c}}$ values close to room temperature; therefore $\mathrm{Nb}$-doped $\mathrm{VO}_{2}$ thin films can be used as intelligent window materials. 


\section{Conclusions and Future Challenges.}

Intelligent thermochromic glass can be made which can switch at temperatures that are practically important: $25-30{ }^{\circ} \mathrm{C}$ and that the precise switching temperature could be chosen by the level of tungsten doping. These coatings were made by a process compatible with and currently used in commercial glass manufacture - APCVD.

The challenges to be overcome in producing a commercial product include:

Colour - the films are yellow / brown in transmission an undesirable colour for glazing. This could be improved by coating the films on a coloured glass, by use of refractive index matched over/under layers or mixtures of dopants.

Scale-up - will the precursor chemistry work on an industrial scale? Some important glazing products such as K-glass and Activ were initially developed on equipment similar to that used in these experiments. It is certainly within the realms of possibility that this process can be scaled up successfully.

Weathering - will the coating survive environmental conditions? This is not necessarily an issue as in a double glazed unit the film could be on an internal surface.

Thermal cycling - will the coating survive repeated temperature cycles? CVD films are generally robust and to date have shown no deterioration in film properties after hundreds of thermal cycles.

There is no doubt that a large market will be available for a commercial thermochromic glass. This will include both household, office and factory window applications through to automotive applications and even for space exploration - a material that can switch its infra-red reflection properties with temperature is very desirable in order to keep space craft components at the correct temperature. It also has potential in fire retardant clothing and in security devices.

\section{Acknowledgements.}

The EU and EPSRC are thanked for financial support. Pilkington Glass are thanked for a supply of substrates and useful discussions. The authors would like to thank Mr. Kevin Reeves for the help with Scanning Electron Microscopy. IPP thanks the Royal Society/ Wolfson Trust for a merit award.

\section{References}

1. Roach, W. Appl. Phys. Lett., 1971, 19, 453.

2. Granqvist, C. G. Advanced Mater., 2003, 15, 1789.

3. Smith, A. W. Appl. Phys. Lett., 1973, 23, 437-438.

4. Granqvist, C. G. Thin Solid Films, 1990, 193/194, 730-741.

5. Richardson M. A.; Coath, J. A. Optics and Laser Technol., 1998, 30, 137-140.

6. Hårsta, A. Chem. Vapor Deposition, 1999, 5, 191-193.

7. Nicholls, J. Mater. World, 1996, 4, 19-21. 
8. Jin. P. "Demonstration of Thermochromic Coating." http://www.aist.go.jp/NIRIN/People/pjin/GIF/tc.gif . 2000.

9. MacChesney J. B.; Guggenheim, H. J. J. Phys. Chem. Solids, 1969, 30, 225-234.

10. Phillips, T. E.; Murray, R. A.; Poehler, T. O. Mater. Res. Bull., 1987, 22, 1113-1123.

11. Pierce, J. W.; Goodenough, J. B. Phys. Rev. B, 1972, 5, 4104-4111.

12. Burkhardt, W.; Christmann, T.; Meyer, B. K.; Niessner, W.; Schalch, D.; Scharmann, A. Thin Solid Films, 1999, 345, 229-235.

13. Livage, J. Coord. Chem. Rev., 1999, 190-192, 391-403.

14. Lee, M. H.; Cho, J. S. Thin Solid Films, 2000, 365, 5-6.

15. Jin, P.; Xu, G.; Tazawa, M.; Yoshimura, M. Jap. J. Appl. Phys., 2002, 41, L278-L280.

16. Mills, A.; Le Hunte, S. J. Photochem. Photobiol. A, 1997, 108, 1-35.

17. O'Neill, S. A.; Parkin, I. P.; Clark, R. J. H. C.; Mills, A.; Elliott, N. J. Mater. Chem., 2003, 13, 56-60.

18. Pilkington ActivTM glass. www.pilkington.com. 2004.

19.

http://www.pilkington.com/pilkington/Corporate/English/company+briefing/glass+manufact uring/floatprocess.htm; "At the heart of the world's glass industry is the float glass process invented by Sir Alastair Pilkington in 1952 - which manufactures clear, tinted and coated glass for buildings, and clear and tinted glass for vehicles. The process, originally able to make only $6 \mathrm{~mm}$ thick glass, now makes it as thin as $0.4 \mathrm{~mm}$ and as thick as $25 \mathrm{~mm}$. Around 260 float plants are in operation, under construction or planned worldwide. Molten glass, at approximately $1000^{\circ} \mathrm{C}$, is poured continuously from a furnace onto a shallow bath of molten tin. It floats on the tin, spreads out and forms a level surface. Thickness is controlled by the speed at which the solidifying glass ribbon is drawn off from the bath. After annealing (controlled cooling) the glass emerges as a 'fire' polished product with virtually parallel surfaces. A float plant, which operates non-stop for between 10-15 years, makes around 6000 kilometres of glass a year in thicknesses of $0.4 \mathrm{~mm}$ to $25 \mathrm{~mm}$ and in widths up to 3 metres. The float process has been licensed to more than 40 manufacturers in 30 countries. There are around 260 float plants worldwide with a combined output of about 800,000 tonnes of glass a week - over $90 \%$ of glass is manufactured from this process".

20. Morin, F. J. Phys. Rev. Lett., 1959, 3, 34-36.

21. Barker, A. S.; Verleur, W. H.; Guggenheim, H. J. Phys. Rev. Lett., 1966, 17, 1286-1289.

22. Verleur, W. H.; Barker, A. S.; Berglund, C. N. Phys. Rev., 1968, 172, 788-798.

23. Rogers, K. D. Powder Diffraction, 1993, 8, 240-244.

24. Becker, M. F.; Buckman, A. B.; Walser, R. M.; Lepine, T.; Georges, P.; Brun, A. Appl. Phys. Lett., 1994, 65, 1507-1509.

25. Mott, N. F. Rev. Modern Phys., 1968, 40, 677-683.

26. Goodenough, J. B. J. Solid State Chem., 1971, 3, 490-500.

27. Hyland, G. J. Rev. Modern Phys., 1968, 40, 739-743.

28. Adler, D.; Brooks, H. Phys. Rev., 1967, 155, 826-840.

29. Adler, D.; Feinleib, J.; Brooks, H.; Paul, W. Phys. Rev., 1967, 155, 851-860.

30. Adler, D. Rev. Modern Phys., 1968, 40, 714-736.

31. Eyert, V. Annalen Der Physik, 2002, 11, 650-702.

32. Tang, C.; Georgopoulos, P.; Fine, M. E.; Cohen, J. B.; Nygren, M.; Knapp, G. S.; Aldred, A Phys. Rev. B, 1985, 31, 1000-1011.

33. Nygren, M.; Israelsson, M. Mater. Res. Bull., 1969, 4, 881-886.

34. Jin, P.; Nakao, S.; Tanemura, S. Thin Solid Films, 1998, 324, 151-158.

35. Jin, P.; Tanemura, S. Jap. J. Appl. Phys., 1995, 34, 2459-2460.

36. Sobhan, M. A.; Kivaisi, R. T.; Stjerna, B.; Granqvist, C. G. Solar Energy Mater. Solar Cells, 1996, 44, 451-455. 
37. Béteille, F.; Livage, J. J. Sol-Gel Sci. Technol., 1998, 13, 915-921.

38. Takahashi, I.; Hibino, M.; Kudo, T. Jap. J. Appl. Phys., 1996, 35, L438-L440.

39. Béteille, F.; Morineau, R.; Livage, J. Mater. Res. Bull., 1997, 32, 1109-1117.

40. Lu, S. W.; Hou, L. S.; Gan, F. X. J. Mater. Sci. Lett., 1996, 15, 856-857.

41. Cavanna, E.; Segaud, J. P.; Livage, J. Mater. Res. Bull., 1999, 34, 167-177.

42. Hanlon, T. J.; Coath, J. A.; Richardson, M. A. Thin Solid Films, 2003, 436, 269-272.

43. Greenberg, C. B. Thin Solid Films, 1983, 110, 73-82.

44. Takahashi, I.; Hibino, M.; Tetsuichi, K., Jap. J. Appl. Phys., 2001, 40, 1391-1395.

45. Jin, P.; Tanemura, S. Thin Solid Films, 1996, 281-282, 239-242.

46. Wu, Z. P.; Miyashita, A.; Yamamoto, S.; Abe, H.; Nashiyama, I.; Narumi, K.; Naramoto, H. J. Appl. Phys., 1999, 86, 5311-5313.

47. Burkhardt, W.; Christmann, T.; Franke, S.; Kriegseis, W.; Meister, D.; Meyer, B. K.; Niessner, W.; Schalch, D.; Scharmann, A. Thin Solid Films, 2002, 402, 226-231.

48. Maruyama, T.; Ikuta, Y; J. Mater. Sci., 1993, 28, 5073-5078.

49. Case, F. C. J. Vac. Sci. Technol. A, 1984, 2, 1509-1512.

50. Rakotoniaina, J. C.; Mokrani-Tamellin, R.; Gavarri, J. R.; Vacquier, G.; Casalot, A.; Calvarin, G. J. Solid State Chem., 1993, 103, 81-94.

51. Guzman, G.; Béteille, F.; Morineau, R.; Livage, J. J. Mater. Chem., 1996, 6, 505-506.

52. Hai-Ning Cui, Vasco Teixeira, Li-Jian Meng, Rong Wang, Jin-Yue Gao, Elvira Fortunato, Thin Solid Films 516 (2008) 1484.

53. Takahshi, Y.; Kanamori, M.; Hashimoto, H.; Moritani, Y.; Masuda, Y. J. Mater. Sci., 1989, 24, 192.

54. Field, M. N.; Parkin, I. P. J. Mater. Chem., 2000, 10, 1863-1866.

55. MacChesney, J. B.; Potter, J. F.; Guggenheim, H. J. J. Electrochem. Soc. Solid State Sci., $1968,115,52-55$.

56. Ryabova, L. A.; Serbinov, A.; Darevsky, A. S. J. Electrochem. Soc., 1972, 119, 427-429.

57. Sahana, M. B.; Dharmaprakash, M. S.; Shivashankar, S. A. J. Mater. Chem., 2002, 12, 333338.

58. Sahana, M. B.; Subbanna, G. N.; Shivashankar, S. A. J. Appl. Phys., 2002, 92, 6495-6504.

59. Barreca, D.; Depero, L. E.; Rizzi, G. A.; Sangaletti, L.; Tondello, E.; Vettori, U. J. Electrochem. Soc., 1999, 146, 551-558.

60. Hitchman, M. L. and Jensen, K. F. Chemical Vapor Deposition, Academic Press, New York, 1993.

61. Rees, W. S.; CVD of Non-Metals, VCH, Weinheim, 1996.

62. Manning, T. D.; Parkin, I. P.; Clark, R. J. H.; Sheel, D.; Pemble, M. E.; Vernadou, D. J. Mater. Chem., 2002, 12, 2936-2939.

63. Manning, T. D.; Parkin, I. P. J. Mater. Chem., 2004, 2554-2559.

64. Manning, T. D.; Parkin, I. P.; Pemble, M. E.; Sheel, D.; Vernardou, D.; Chem. Mater.; 2004; 16(4); 744-749.

65. Cross, W. B.; Parkin, I.P. Chem. Comm., 2003, 14, 1696.

66. Binions, R.; Carmalt, C. J.; Parkin, I. P.; Thin Sol. Films, 2004, 469-470, 416.

67. Choy, K.L.; Progr. Mater. Sci., 2003, 48, 57-170.

68. Piccirillo, C.; Binions, R.; Parkin, I. P.; Chem. Vap. Dep., 2007, 13 (4), 145.

69. Piccirillo, C.; Binions, R.; Parkin, I. P.; Thin Sol. Films, in press.

70. Manning, T.D.; PhD thesis, London, 2004.

71. Piccirillo, C.; Binions, R.; Parkin, I. P.; Europ. J. Inorg. 2007, 254050. 